\title{
CONTRA A PERFEIÇÃO, O MELHORAMENTO HUMANO OU PELA DÁDIVA? UMA ANÁLISE DOS ARGUMENTOS DE MICHAEL SANDEL SOBRE
}

\section{A ENGENHARIA GENÉTICA *}

Against perfection, human enhancement or for the gift? An analysis of Michael Sandel's arguments on genetic engineering

Murilo Mariano Vilaça **

Resumo: No presente artigo, apresento e analiso criticamente os argumentos de Michael Sandel contra os usos não terapêuticos (ou melhoradores) da engenharia genética. Parto de considerações sobre algumas tendências presentes no debate bioético (seção 1) e do delineamento da vertente bioconservadora/antimelhoramento (seção 2), à qual Sandel está associado. Após, destaco o modo como ele utiliza o conceito de dádiva para criticar a perfeição/o melhoramento, aplicando-o a dois casos específicos, melhoramento genético de atletas e da descendência, retórica sobre a qual faço algumas ponderações críticas (seção 3). Com base nestas, concluo que o conceito de dádiva não é adequado para sustentar uma proscrição moral do biomelhoramento humano em sociedades livres e pluralistas.

Palavras-chave: Engenharia genética. Perfeição. Melhoramento humano. Dádiva. Michael Sandel.

Abstract: In this article, I present and critically analyze Michael Sandel's arguments against the non-therapeutic (or enhancement) uses of genetic engineering. I start with considerations about some trends in the current bioethical debate

\footnotetext{
* Artigo recebido em 03/02/2021 e aprovado para publicação em 30/11/2021.

** Doutor em Filosofia pelo Programa de Pós-Graduação em Filosofia da Universidade Federal do Rio de Janeiro. Pesquisador Associado da Fundação Oswaldo Cruz. Docente Permanente do Programa de Pós-Graduação em Bioética, Ética Aplicada e Saúde Coletiva (PPGBIOS). Coordenador do Grupo de Investigações Filosóficas sobre Transumanismo e Biomelhoramento Humano (GIFT-H+). Pesquisador da FAPERJ.
} 
(section 1), followed by an outline of the bioconservative or anti-enhancement perspective (section 2), assumed by Sandel. I then highlight the way Sandel uses the concept of gift to criticize perfection/enhancement, applying it to two specific cases, the genetic enhancement of athletes and offspring, rhetoric about which I make some critical considerations (section 3). From this, I conclude that the concept of gift is not adequate to sustain a moral ban on human enhancement in free and pluralistic societies.

Keywords: Genetic engineering. Perfection. Human enhancement. Gift. Michael Sandel.

\section{Introdução}

$\mathrm{H}$ á muito, reflexões em torno da ciência e da técnica têm sido formuladas em diversos campos da filosofia. Atualmente, um dos focos do debate filosófico diz respeito às questões éticas relativas aos potenciais biomédicos/biotecnológicos que ultrapassam os objetivos terapêuticos. O chamado Human Enhancement - que traduzirei como melhoramento, melhoramento biomédico ou biomelhoramento humano - é um dos temas em ética prática/aplicada ou bioética mais relevantes na atualidade.

Embora o debate seja muito complexo, envolvendo múltiplos conceitos e perspectivas bastante distintas, uma polarização tem sido apresentada para enquadrá-lo. Enquanto alguns defenderiam que os usos da biotecnologia deveriam se restringir às intervenções terapêuticas, outros entenderiam que usos melhoradores também seriam moralmente admissíveis, desejáveis e, no limite, até mesmo obrigatórios. De um lado, então, estariam os chamados de bioconservadores. Do outro, os chamados transumanistas.

Neste artigo, analiso criticamente os argumentos apresentados por Michael J. Sandel no livro Contra a perfeição: ética na era da engenharia genética. ${ }^{1} \mathrm{Na}$ primeira seção, faço algumas considerações sobre algumas tendências presentes no debate bioético. Na segunda, caracterizo brevemente a linha pensamento bioconservadora/antimelhoramento ${ }^{2}$, à qual Sandel está associado, destacando características gerais e algumas diferenças entre alguns dos seus mais destacados representantes. Na terceira, analiso os pontos centrais da retórica sandeliana, submetendo-os a ponderações e objeções.

\footnotetext{
${ }^{1}$ SANDEL, M. Contra a perfeição: ética na era da engenharia genética. Rio de Janeiro: Civilização Brasileira, 2013.

${ }^{2}$ Antimelhoramento (para nomear os bioconservadores) e anti-antimelhoramento (para nomear os transumanistas) são termos sugeridos por BUCHANAN, A. Beyond Humanity? The Ethics of Biomedical Enhancement. Oxford: Oxford University Press, 2011.
} 


\section{Comentários sobre a tendência ideologizante do debate bioético}

De acordo com Junges ${ }^{3}$, o debate bioético em torno da moralidade dos usos da biotecnologia é marcado por três tendências interligadas, a saber, dilemática, ideológica e ativista/militante. Segundo Junges ${ }^{4}$, a primeira tendência se expressa na redução de um debate sobre um tema complexo a duas posições antagônicas - pró versus contra - de modo que as respostas para os problemas ou desafios éticos envolvidos ficam restritos a duas possibilidades diametralmente opostas. Dessa forma, problemas são transformados em dilemas, impondo uma polarização que obstrui o debate e a deliberação.

A segunda tendência é caracterizada pelo predomínio de um significado fraco de ideologia, caracterizado pela generalização da determinação social do pensamento. Nesse sentido, ideológico é algo (crença, conduta, linha de pensamento, posição política, etc.) que seria tipificado por alguns traços: mentalidade dogmática, comportamento doutrinário e forte componente passional. O dogmativismo é caracterizado por uma impermeabilidade a argumentos e fatos contrários à crença esposada. O doutrinarismo se revela na adoção de princípios arbitrários e de premissas não comprovadas, a partir dos quais se desenvolve uma problemática argumentação dedutiva. Tais elementos se unem ao componente passional, ensejando a terceira tendência (ativismo militante)..$^{5}$

Fortemente influenciado por um viés político-ideológico-polarizante-militante, o debate bioético ganha, muitas das vezes, um contorno panfletário, marcado pela adoção de um discurso-ação/discurso ideológico, no qual conceitos teóricos são usados com fins práticos, operando antecipações verbais de um futuro sobre o qual se quer influir. ${ }^{6}$ Adotando o que Bazzan ${ }^{7}$ denomina de artifícios tííicos da política moderna, divide-se o debate em correntes que compartilham certas percepções e representações, as quais são disseminadas por meio de verdadeiros slogans de folhetos, cujo propósito é influenciar o público, inibindo-o ou mobilizando-o. Às expensas do melhor argumento, de abordagens explicativas e ponderadas, posturas ideológicas, apologéticas e hiperbólicas são erigidas sobre alegações carentes de fundamento.

Como efeito disso, Buchanan ${ }^{8}$ identifica a presença de aspectos frustrantes no debate sobre o melhoramento biomédico, que seria marcado por

\footnotetext{
${ }^{3}$ JUNGES, J. R. Falácia dilemática nas discussões da bioética. Revista Bioética (CFM), v. 27, n. 2, 2019, p. 196-203.

${ }^{4}$ Ibid.

${ }^{5}$ Ibid.

${ }^{6}$ BAZZAN, M. R. A ideologização de 'Rousseau' no teatro da revolução francesa. Kriterion (UFMG), v. 61, n. 146, 2020, p. 481-500.

${ }^{7}$ Ibid.

${ }^{8}$ BUCHANAN, op. cit., 2011.
} 
retóricas obscuras mascaradas como argumentação, por uma enxurrada de afirmações sem amparo em fatos (ausência de evidências empíricas) e pela dicotomia pró versus contra. Ele, que é uma referência no debate bioético, afirma:

Que eu saiba, não há nenhuma outra parte da literatura de Ética Prática em que escritores acadêmicos continuem, em face de críticas articuladas, justas e poderosas, a implantar bordões e slogans grandiosos, mas profundamente ambíguos no cerne de seus pontos de vista, e nunca se deem ao trabalho de tentar traduzi-los em argumentos sólidos. ${ }^{9}$

Essa caracterização do campo bioético e do debate em torno do biomelhoramento humano revela alguns sérios embaraços ao desenvolvimento de um debate qualificado, que dê conta das exigências teóricas e implicações práticas de temas complexos que são irredutíveis a simplificações polarizadoras e a uma postura militante, ainda que muito bem intencionada (por exemplo, em defesa da vida, da natureza e da dignidade humanas). Essas observações indicam que é necessário tomar rígidos cuidados no debate filosófico sobre os usos da biotecnologia, a começar pelas opções lexicais feitas, a fim de não criar um enviesamento terminológico-ideológico, incorrendo em simplificações, polarizações e alegações falaciosas. Tendo isso em mente, passo à próxima seção, em que abordarei a perspectiva antimelhoramento.

\section{Perspectiva antimelhoramento: caracteristicas gerais de uma vertente}

Não é infrequente que uma linha de pensamento, embora possa ser genericamente caracterizada, apresente importantes variações internas. Isso ocorre no caso da vertente antimelhoramento, já que seus diferentes componentes focalizam aspectos variados do tema, desenvolvendo linhas argumentativas com semelhanças, mas também com particularidades. Nesta seção, buscarei pôr em destaque algumas ideias fundamentais compartilhadas pelos pensadores antimelhoramento, sem desconsiderar as diferenças entre suas abordagens.

Em regra, os autores dessa vertente - como o termo antimelhoramento indica - defendem que não devemos ultrapassar o campo terapêutico em direção ao campo do biomelhoramento. Para eles, isso poria em risco, por exemplo, a natureza ${ }^{10}$, dignidade, igualdade, autonomia, identidade

\footnotetext{
${ }^{9}$ Ibid., p. 3.

${ }^{10}$ Para não 'poluir' o texto, utilizarei o termo natureza sem aspas, embora não o reconheça como o conceito claro e preciso.
} 
e liberdade humanas. Adotando acepções variadas desses conceitos, os autores vislumbram graves consequências das intervenções sobre a biologia humana com o propósito de melhorar certas funções ou capacidades (cognitivas, físicas, morais, de humor, etc.).

Considerando a axial relevância desses conceitos, sobretudo para as sociedades ocidentais, bem como a importância dessas funções humanas, tal perturbadora ameaça deveria provocar as mais intransigentes resistências, não havendo dúvidas de que o biomelhoramento deveria ser proibido. Contudo, há controvérsias acerca dos fundamentos das relações estabelecidas pelos pensadores antimelhoramento, bem como sobre a procedência dos seus temores. ${ }^{11,12,13}$

O biomelhoramento humano pode ser definido de diversas formas, sendo abordado desde variadas perspectivas. Savulescu, Sandberg e Kahane ${ }^{14}$, por exemplo, citam cinco abordagens possíveis: sociológico-pragmática, ideológica, não-médica, funcional e bem-estarista. Tais abordagens e os respectivos sentidos atribuídos ao conceito estão mais ou menos presentes entre os antimelhoramento e os anti-antimelhoramento. Não obstante, as abordagens ideológica e não-medical são as que identificam, de modo paradigmático, a vertente antimelhoramento. Segundo os autores, a abordagem ideológica caracteriza-se por "[...] visar diretamente a valores profundos, invocando conceitos da metafísica ou espiritualidade", aplicando "[...] um conjunto de valores frequentemente controversos [...] a uma gama de possíveis avanços tecnológicos [...]"15, classificando estes como moralmente bons ou problemáticos. A abordagem não-médica, por sua vez, é caracterizada pela tese de que terapias e melhoramentos são tipos radicalmente distintos de intervenção sobre a natureza humana. Em linhas gerais, o primeiro tipo visaria à manutenção ou restauração da saúde, por meio do tratamento de doenças, tendo como parâmetro um nível tido como normal acerca do que é chamado de funcionamento típico da espécie. $\mathrm{O}$ segundo diria respeito às intervenções que ultrapassam o limite definido pelo binômio saúde-normalidade. ${ }^{16}$

\footnotetext{
${ }^{11}$ DIAS, M. C.; VILAÇA, M. M. Metamorfoses do humano: notas sobre o debate ético em torno da biotecnologia para o aperfeiçoamento humano. Ethic@ (UFSC), v. 9, n. 1, 2010, p. 29-42. ${ }^{12}$ DIAS, M. C.; VILAÇA, M. M. Natureza humana versus aperfeiçoamento? Uma crítica aos argumentos de Habermas contra a eugenia positiva. Princípios - Revista de Filosofia (UFRN), v. 20, n. 33, 2013, p. 227-263.

${ }^{13}$ VILAÇA, M. M. Levando o transumanismo a sério - isso não é uma apologia! In: OLIVEIRA, J.; LOPES, W. E. S. (Orgs.). Transumanismo: o que é, quem vamos ser. Caxias do Sul: Educs, 2020, p. 135-160.

${ }^{14}$ SAVULESCU, J.; SANDBERG, A.; KAHANE, G. Well-Being and Enhancement. In: SAVULESCU, J.; MEULEN, R. t.; KAHANE, G. (Eds.). Enhancing Human Capacities. Oxford: Wiley-Blackwell, 2011, p. 3-18.

${ }^{15}$ Ibid., p. 4.

${ }^{16}$ Ibid.
} 
Um ponto de partida fundamental compartilhado pelos pensadores antimelhoramento é a pressuposição da existência de uma fronteira clara entre terapia e melhoramento, e que ela teria valor normativo. Outro ponto em comum é que a admissibilidade e exclusividade morais da terapia se baseariam em dois conceitos: no de natureza humana, que, com isso, assume uma função transcendental, ou seja, a partir da qual as práticas humanas devem ser orientadas; e no de normalidade, conceito empírico-estatístico que assume uma função normativa, transformando-se numa espécie de conceito espesso/denso (thick concept). Como as intervenções terapêuticas visariam à normalidade da natureza humana, elas têm respaldo moral. As biointervenções melhoradoras, ao contrário, na medida em que ultrapassariam os limites da normalidade da natureza humana, não teriam. A partir desse entendimento básico, alegações e prognósticos temerários são dispostos no debate acerca do biomelhoramento humano.

De acordo com Dias e Vilaça ${ }^{17}$, os pensadores da corrente antimelhoramento podem ser definidos como protecionistas pessimistas. Com esta expressão, Dias e Vilaça reúnem duas características fundamentais do pensamento antimelhoramento, a saber, a defesa da natureza humana e um temor difuso, hiperbólico. ${ }^{18}$ Com isso, os bioconservadores prognosticam uma ampla gama de ameaças à natureza humana decorrente dos usos não terapêuticos das biotécnicas.

Conforme Bostrom ${ }^{19}$, há a presença de uma heurística do temor ou medo (Heuristic of Fear) em muitas das abordagens antimelhoramento, tendência que pode ter uma inspiração em Hans Jonas. No último tópico do famoso livro O princípio da responsabilidade, intitulado Preservar a "imagem $e$ semelhança", Jonas, com a adoção de alguns termos e expressões com teor marcadamente religioso (sagrado, imagem e semelhança, etc.), afirma:

Também temos novamente de recuperar o respeito e o medo que nos projetam dos descaminhos do nosso poder (por exemplo, de experimentos com a constituição humana). O paradoxo da situação atual está em que precisamos recuperar esse respeito a partir o medo $[\ldots] .^{20}$

Nesse sentido, em resposta à pergunta sobre como pôr em prática a precaução, diante dos riscos, Jonas propõe a admissão de um aforismo singelo: "[...] in dubio pro malo - no caso de dúvida, dar ouvidos ao pior

\footnotetext{
${ }^{17}$ DIAS; VILAÇA, op. cit., 2013.

${ }^{18}$ KASS, L. R. Life, liberty and the Defense of Dignity. San Francisco: Encounter Books, 2002. Ao se referir ao Playing God, Kass admite que há um discurso hiperbólico, embora, na visão dele, isso não invalidasse as preocupações apresentadas pelos bioconservadores.

${ }^{19}$ BOSTROM, N. A History of Transhumanist Thought. Journal of Evolution and Technology, v. 14, n. 1,2005, p. $1-25$.

${ }^{20}$ JONAS, H. O princípio responsabilidade: ensaio de uma ética para a civilização tecnológica. Rio de Janeiro: Contraponto; Ed. PUC-Rio, 2006, p. 353.
} 
prognóstico do que ao melhor". ${ }^{21}$ Essa, segundo o autor, é a regra fundamental do princípio da responsabilidade. Jonas ${ }^{22}$ considera o medo como uma obrigação que, ao lado do tremor, constitui a fonte de uma ética da responsabilidade que seria necessária às sociedades tecnocientificamente avançadas, defendendo que devemos manter o patrimônio humano semelhante ao que ele é e guardá-lo intacto.

De acordo com Gordon, Burckhart e Segler ${ }^{23}$, a heurística do temor ou medo é tipicamente um princípio de precaução conservador, segundo o qual, no que diz respeito aos imprevisíveis efeitos do desenvolvimento tecnológico, deve-se priorizar o mau prognóstico em relação ao bom prognóstico. Tal princípio pode ser identificado, explicita ou implicitamente, em vários pensadores antimelhoramento. Segundo Harris, "as discussões sobre a ética da manipulação genética ou da clonagem reprodutiva humana são atormentadas por apelos à santidade do pool genético humano ou à importância de preservar a herança genética da humanidade" ${ }^{24}, \mathrm{o}$ que, ainda de acordo com o autor, envolve o amplamente aceito, mas incoerente princípio da precaução. Harris lista uma série de suposições questionáveis presentes no princípio, concluindo que ele não oferece uma base racional que contemple, ao mesmo tempo, a defesa da interrupção da intervenção sobre algo (leaving things alone) e a priorização do que já está dado (status quo).

À guisa de encerramento dessa seção, além da pressuposição da fronteira entre terapia e melhoramento; da defesa de uma suposta natureza humana compartilhada pelos espécimes humanos, que serviria como fundamento para os direitos humanos e para a moralidade, que alegadamente estaria sob grave risco; bem como da heurística do temor/medo acerca dos usos melhoradores dos avanços biotecnológicos, a corrente antimelhoramento caracteriza-se pela(o): ideia de que algo nos foi dado (given) pela natureza, por Deus ou pelo acaso, um talento ou dádiva que deve ser recebido com gratidão, humildade e respeito, de modo que modificá-lo alteraria a nossa natureza e seria um indicativo de desrespeito e arrogância (hubris); recurso a elementos (princípios, intuições e, até mesmo, dogmas) de uma perspectiva religiosa (que pode ser chamada de judaico-cristã) para basear suas alegações; menção a obras de ficção distópicas, quer literárias, quer cinematográficas; e forte crítica ao transumanismo e à pós-humanidade.

${ }^{21}$ JONAS, H. Técnica, medicina y ética: sobre la práctica del principio de responsabilidad. Barcelona: Paidós Ibérica Edicioones, 1997, p. 49.

22 JONAS, op. cit., 2006.

${ }^{23}$ GORDON, J-S.; BURCKHART, H.; SEGLER, P. Introduction. In: GORDON, J-S.; BURCKHART, H. (Eds.). Global Ethics and Moral Responsibility: Hans Jonas and His Critics. New York: Routledge, 2014, p. 1-8.

${ }^{24}$ HARRIS, J. Enhancement Are a Moral Obligation. In: SAVULESCU, J.; BOSTROM, N. (Eds.). Human Enhancement. Oxford University Press, 2009, p. 131-154, p. 132. 
Tendo em mente Francis Fukuyama ${ }^{25,26}$, Leon $\operatorname{Kass}^{27,28}$, Jürgen Habermas ${ }^{29}$ e Michael Sandel ${ }^{30}$, faço, abaixo, breves destaques acerca da diferencial presença desses elementos em suas respectivas linhas argumentativas.

Em relação à fronteira terapia/melhoramento e ao conceito de natureza humana, a variação de ênfase não me parece digna de nota, haja vista serem elementos que estão na base das suas argumentações. Não obstante, enquanto alguns apelam ao temor/medo de modo incisivo, hiperbólico e panfletário (como Fukuyama e Kass), outros o fazem de modo mais direcionado/pontual e, em alguma medida, complexamente argumentado (como Habermas) ou de modo menos incisivo/mais interrogativo ou especulativo (como Sandel), o que não significa, absolutamente, que estes não focalizem os riscos em vez dos benefícios, privilegiando o mau prognóstico. No que diz respeito aos conceitos de talento e dádiva, Sandel e Kass se destacam, utilizando-os profusamente, enquanto Fukuyama o cita pontualmente e Habermas sequer o menciona. Quanto ao apelo à religião e a ficções distópicas, Habermas destoa dos outros três pensadores ${ }^{31}$, os quais recorrem a elementos de uma perspectiva religiosa de mundo (notadamente cristã) e a elementos ficcionais ${ }^{32}$ para alicerçar pontos da sua argumentação (Fukuyama mais do que Kass, e este mais do que Sandel). Em relação ao transumanismo/transumano e pós-humanidade/pós-humano, alguns sequer os mencionam (como Habermas e Sandel), ao passo que outros os enfatizam na sua argumentação contra o biomelhoramento humano (Kass) e/ou os tomam como alvo de ataque direto (Fukuyama).

Tais diferenças são relevantes e servem de alerta contra generalizações apressadas. Todavia, os pensadores antimelhoramento compartilham o entendimento fundamental de que as sérias ameaças à humanidade provenientes dos usos não terapêuticos da biotecnociência representariam motivos suficientes para proibi-los.

Sem desconsiderar os limites da exposição acima, penso que ela seja suficiente para destacar alguns dos pontos centrais do pensamento an-

\footnotetext{
${ }^{25}$ FUKUYAMA, F. Nosso futuro pós-humano: consequências da revolução biotecnológica. Rio de Janeiro: Rocco, 2003.

${ }^{26}$ FUKUYAMA, F. Transhumanism - The World's Most Dangerous Idea. Revised Version, 2019. Disponível em: https://www.au.dk/fukuyama/boger/essay/. Acesso em: 17 nov. 2020.

${ }^{27}$ KASS, op. cit., 2002.

${ }^{28}$ KASS, L. R. et al. Beyond Therapy: Biotechnology and the Pursuit of Happiness. A Report by the President's Council on Bioethics. New York: Harper Collins, 2003.

${ }^{29}$ HABERMAS, J. O futuro da natureza humana: a caminho de uma eugenia liberal? São Paulo: Martins Fontes, 2004.

${ }^{30}$ SANDEL, op. cit., 2013.

${ }^{31}$ Habermas, certamente, oferece a argumentação mais secular e menos ficcional entre os autores citados.

${ }^{32}$ O filme Gattaca (citado por Sandel) e os livros Abolição do homem, de C. S. Lewis, e Admirável mundo novo, de Aldous Huxley (citados por Kass e Fukuyama), são os mais frequentemente presentes.
} 
timelhoramento, sem desconsiderar a indicação de diferenças entre seus representantes. Assim, passo a apresentar os argumentos de Sandel, interpondo algumas ponderações e objeções.

\section{Contra a perfeição e o biomelhoramento, a favor da dádiva: ponderações e objeções sobre pontos-chave da retórica sandeliana}

Em seu livro dedicado a um tema da ética aplicada, dividido em cinco capítulos $^{33}$ e um epílogo ${ }^{34}$, Sandel faz uma abordagem ética da engenharia genética por meio de casos selecionados. ${ }^{35}$ Com um título sugestivo, Sandel destaca o conflito entre contemplar e dominar a natureza humana, defendendo os valores da humildade, responsabilidade e solidariedade concernentes às noções de dom, talento, dádiva (gift/giftedness), a fim de criticar nosso impulso ao domínio (mastery). Em defesa dos talentos naturais e da abertura à imprevisibilidade, Sandel contesta a manipulação da natureza humana para fins de melhoramento, planejamento, controle e determinação do que somos ou queremos ser. ${ }^{36}$

Nas palavras do filósofo,

Reconhecer o aspecto de dádiva da vida é reconhecer que nossos talentos e nossas potências não são mérito unicamente nosso; não são sequer completamente nossos [...]. É também reconhecer que nem tudo no mundo está aberto a qualquer tipo de uso que possamos desejar ou imaginar. A valorização do aspecto de dádiva da vida restringe o projeto prometeico e conduz a certa humildade. Apesar de em parte ser uma sensibilidade religiosa, seus ecos ressoam para além da religião. ${ }^{37}$

Em resposta à questão sobre "o que se perderia caso a biotecnologia dissolvesse nosso senso de dádiva?" 38 , Sandel afirma:

Do ponto de vista da religião, a resposta é clara: acreditar que nossos talentos e nossas potências se devam unicamente a nós mesmos é não compreender nosso lugar na criação, confundir nosso papel com o de Deus. A religião, contudo, não é a única fonte de motivos para nos importarmos com aquilo que nos é dado de modo inato, ou como dádiva. Os riscos morais podem

\footnotetext{
${ }^{33}$ 1. A ética do melhoramento; 2. Atletas biônicos; 3. Filhos projetados, pais projetistas; 4. A nova e a velha eugenias; 5 . Domínio e talento.

34 Ética embrionária: o debate sobre as células-tronco

${ }^{35}$ Atletas modificados geneticamente ou atletas biônicos; e filhos projetados geneticamente pelos pais; uso de células-tronco embrionárias humanas.

${ }^{36}$ SANDEL, op. cit., 2013.

${ }^{37}$ Ibid, p. 41.

${ }^{38}$ Ibid., p. 98-99.
} 
também ser descritos em termos seculares. Se a revolução genética erode nossa valorização do caráter de dádiva dos poderes e conquistas humanos é porque transforma três características cruciais de nossa configuração moral: a humildade, a responsabilidade e a solidariedade.

Para ele, no melhoramento,

os maiores riscos são de dois tipos. Um deles envolve o destino dos bens humanos encarnados em importantes práticas sociais - os preceitos de amor incondicional e abertura ao imprevisto, no caso da experiência parental; a celebração dos talentos e dos dons naturais nas artes e nos esportes; a humildade diante do privilégio próprio e a disposição de partilhar os frutos da sua boa fortuna por meio de mecanismos de solidariedade social. $\mathrm{O}$ outro diz respeito a nossa orientação em relação ao mundo que habitamos e ao tipo de liberdade ao qual aspiramos. ${ }^{39}$

No epílogo do seu livro, Sandel afirma que o que o preocupa "[...] não é o melhoramento como vício individual, mas sim como hábito mental e modo de vida"40 e que, numa espécie de síntese da sua abordagem, "ao me opor ao melhoramento genético, argumentei contra o triunfo unilateral do domínio sobre a reverência e insisti que voltássemos a valorizar a vida como uma dádiva". ${ }^{41}$

Abaixo, apresento o modo como o conceito de dádiva é utilizado por Sandel para defender sua posição antimelhoramento. Enfatizo as principais alegações do autor em torno dos esportes (talentos naturais como dádiva) e da relação entre pais e filhos (filhos como dádiva), interpondo minhas objeções e ponderações. Antes, porém, farei algumas considerações sobre a seleção lexical feita pelo autor para intitular a sua obra.

No título, vê-se uma espécie de declaração de intenção, posicionar-se contra alguma coisa, a saber, a perfeição. Além de informar algo explicitamente, o autor sugere algo implicitamente. Afinal, posicionar-se contra a perfeição implica supor que haja alguém que a defenda. Com o subtítulo, fica indicado que a perfeição seria alcançada por meio da engenharia genética. Assim, o autor parece sugerir ao leitor que existe, de um lado, uma vertente que defende a busca pela perfeição por meio da manipulação genética, e, do outro, uma que vai de encontro a essa ideia. E é desta que Sandel faria parte.

De saída, cabe ressaltar que o termo perfeição não caracteriza a perspectiva dos pensadores anti-antimelhoramento, servindo de eixo ou frontispício da sua argumentação. Aliás, pode-se plausivelmente afirmar que, prototipicamente, há uma resistência à ideia de perfeição por parte deles. Diante

\footnotetext{
${ }^{39}$ Ibid., p. 106.

${ }^{40}$ Ibid., p. 106.

${ }^{41}$ Ibid., p. 111.
} 
da impossibilidade de fazer uma ampla revisão dos textos, recorrerei a um texto-documento que foi produzido/publicado no âmbito da World Transhumanist Association (WTA) e é subscrito por uma variedade bastante representativa de pensadores que defendem a moralidade do biomelhoramento humano. Logo no início do The Transhumanist FAQ, lê-se que "podemos não ser perfeitos, mas podemos melhorar as coisas promovendo o pensamento racional, a liberdade, a tolerância, a democracia e a preocupação com os outros seres humanos". ${ }^{42}$ Mais à frente, em resposta à questão que intitula o item 6.6 do mesmo texto-documento (não seria chato viver para sempre em um mundo perfeito?), lê-se que:

"Perfeição" é uma palavra vaga e traiçoeira. Há uma discordância considerável entre os transumanistas sobre que tipo de perfeição é alcançável e desejável, seja na teoria ou na prática. Provavelmente, é mais sensato falar em melhorar o mundo, em vez de torná-lo "perfeito". 43

Max More sintetiza e expressa precisamente o ponto para o qual estou chamando a atenção. Endossando os princípios do progresso perpétuo e da autotransformação, More afirma que eles "[...] expressam claramente a implementação do transumanismo como sendo um processo contínuo, e não sobre a busca de um estado de perfeição. ${ }^{44}$

Resumindo, além de a perfeição não poder ser um objetivo amplamente atribuído aos anti-antimelhoramento, estes, prototipicamente, rejeitam a ideia de perfeição, bem como discordam do entendimento de que modificar a natureza humana seria um ato de arrogância ${ }^{45}$, o que indica um problema sobre o modo como Sandel intitula sua abordagem.

Feita a ressalva sobre o uso do termo perfeição, passo a analisar os argumentos de Sandel contra o melhoramento.

No capítulo 1, intitulado a ética do melhoramento, Sandel introduz sua perspectiva, abordando, com certa brevidade, uma pequena variedade de possibilidades terapêuticas que a engenharia genética estaria colocando à disposição das pessoas, mas que poderiam também ser utilizadas como biotécnicas de melhoramento e seleção (melhoramento muscular, da memória, da estatura e seleção de características da descendência, incluindo

\footnotetext{
${ }^{42}$ BOSTROM, N. et al. The Transhumanist FAQ. World Transhumanist Association, version 2.1. 2003, p. 4. Disponível em: https://www.nickbostrom.com/views/transhumanist.pdf. Acesso em: 16 nov. 2020.

${ }^{43}$ Ibid., p. 52.

${ }^{44}$ MORE, M. The Philosophy of Transhumanism. In: MORE, M.; VITA-MORE, N. (Eds.). The Transhumanist Reader. Chichester, UK: Wiley-Blackwell, 2013, p. 3-17; p. 5; grifos meus. ${ }^{45}$ BOSTROM, N. Transhumanist Values. Review of Contemporary Philosophy, v. 4, issue 1-2, 2005, p. 87-101.
} 
o sexo). Abrindo os braços ${ }^{46}$ para as possibilidades terapêuticas, mas 'os fechando' para as aplicações, Sandel afirma que tais biotécnicas geram, ao mesmo tempo, uma promessa e um dilema:

A promessa é que em breve seremos capazes de tratar e prevenir uma série de doenças debilitantes. O dilema é que nosso recém-descoberto conhecimento genético também pode permitir a manipulação de nossa própria natureza - para melhorar nossos músculos, nossa memória e nosso humor; para escolher o sexo, a altura e outras características genéticas de nossos filhos; para melhorar nossas capacidades física e cognitiva; para nos tornar "melhores do que a encomenda". ${ }^{47}$

Para ele, "o dilema moral surge quando as pessoas utilizam [...] terapias não para curar uma doença, e sim para ir além da saúde, para melhorar suas capacidades físicas ou cognitivas, para erguer-se acima da norma geral" ${ }^{48}$

Para Sandel, o que deve tornar o biomelhoramento eticamente inquietante são os desejos e os fins almejados, e não os meios utilizados. No caso do melhoramento de si, a questão seria por que desejamos ter músculos e memória melhores do que o normal. Quanto a essas modalidades de melhoramento, Sandel - acertadamente, a meu ver - afirma que as alegações de (in)justiça, de (des)igualdade e (in)segurança não são decisivas. Tomando como exemplo o caso dos esportes, ele afirma que

Sempre houve atletas geneticamente superiores e, contudo, não julgamos que a desigualdade natural da herança genética de uns em relação a outros prejudique a justiça nas competições esportivas. Do ponto de vista da justiça e da igualdade competitiva, as diferenças genéticas provocadas pelo melhoramento não são piores do que as naturais. Além do mais, supondo que seu uso seja seguro, as terapias de melhoramento genético poderiam estar disponíveis para todos. Se o melhoramento genético nos esportes é moralmente censurável, então deve sê-lo por motivos que vão além da justiça e da igualdade". ${ }^{49}$

No caso do planejamento e seleção da descendência, a questão fundamental, para Sandel, não seria que características queremos ou não queremos que nossos filhos tenham. O problema seria querermos um design de filho/ filha, manipulando a sua concepção para interferir na loteria genética, ou seja, debelar da vida humana o fator imprevisibilidade.

Na sua crítica, Sandel rejeita o argumento da autonomia - que é utilizado, por exemplo, por Habermas ${ }^{50}$ - uma vez que ele

\footnotetext{
${ }^{46}$ SANDEL, op. cit., 2013, p. 23: “Todos deveriam receber de braços abertos uma terapia genética $[\ldots]^{\prime \prime}$.

${ }^{47}$ Ibid., p. 19.

${ }^{48}$ Ibid., p. 21.

${ }^{49}$ Ibid., p. 25.

${ }^{50}$ HABERMAS, op. cit., 2004.
} 
[...] implica erroneamente que, na ausência de um progenitor projetista, as crianças sejam livres para escolher suas características físicas. Ninguém, entretanto, escolhe a própria herança genética. A alternativa a uma criança clonada ou geneticamente melhorada não é uma criança cujo futuro está isento de restrições e do escopo de talentos específicos, mas sim uma criança que está à mercê da loteria genética..$^{51}$

Sandel também rejeita o argumento do acesso, alegando que a garantia de acesso ao biomelhoramento não resolveria o que seria é o problema central, isto é, se devemos aspirar a ele.

Para Sandel, a despeito das questões de justiça, igualdade, segurança e autonomia poderem ser refutáveis pelos defensores do melhoramento humano,

em todos esses casos, persiste algo de moralmente inquietante. O problema não reside somente nos meios, mas também nos fins almejados. É comum dizer que o melhoramento genético, a clonagem e a engenharia genética ameaçam a dignidade humana. Isso é verdade. O desafio, porém, é identificar como essas práticas reduzem a nossa humanidade - ou seja, quais aspectos da liberdade humana ou do florescimento humano se veem ameaçados. ${ }^{52}$

Apontando os limites dos conceitos que compõem a linguagem tradicional das sociedades liberais (autonomia, igualdade, justiça e direitos humanos) para efeito de compreensão e análise dos temas e questões despertados pela engenharia genética e pela possibilidade de reegenharia da nossa natureza, Sandel defende que "para compreender a ética do melhoramento, precisamos enfrentar questões que há muito se ausentaram do campo de visão do mundo moderno - relativas ao estatuto moral da natureza e à atitude adequada dos seres humanos em relação ao mundo 'dado'", 53

Em suma, no cerne da sua argumentação estão traços da perspectiva antimelhoramento. Confere-se às possibilidades terapêuticas o caráter de promessa e às possibilidades melhoradoras o de ameaça, criando a oposição dilemática. Enquanto as aplicações terapêuticas seriam bem-vindas, o melhoramento ameaçaria elementos fundamentais de uma concepção de natureza/condição humana tida como natural.

Sobre esses pontos iniciais, cabem algumas ponderações. Em primeiro lugar, destaco que há sérios problemas morais envolvidos em terapias, tanto em relação ao que visam a tratar quanto aos meios empregados, objetivos visados e efeitos gerados. Se considerarmos apenas as chamadas anormalidades/doenças do espectro mental-comportamental, tratamentos já foram oferecidos para ajustar comportamentos tidos, hoje, como legíti-

${ }^{51}$ SANDEL, op. cit., 2013, p. 20-21.

${ }^{52}$ Ibid., p. 35.

${ }^{53}$ Ibid., p. 22. 
mos ou perfeitamente normais. 'Tratava-se' algo, apenas por ele ser tido, à época, como algo desviante, fora da norma geral. Assim, terapias têm sido utilizadas como instrumento de forte controle sobre condutas, expressando um desejo de domínio arbitrário sobre a vida humana. Há, nesse sentido, graves efeitos da chamada hipermedicalização da vida humana, das sociedades, dos comportamentos, dos problemas sociais. Dito isso, licenciar tudo que se apresente como uma terapia, uma vez que serviria para nos conduzir à norma geral (à normalidade), representa um entendimento controvertido não só do ponto de vista teórico, mas também histórico.

Quanto à distinção entre normal e anormal, ela não existe para além de um contexto, não é um dado atemporal ou a expressão de um parâmetro claro, universal e imutável ao qual temos que nos submeter inquestionavelmente. ${ }^{54}$ Tais noções enquadram um espectro muito variável de uma mesma capacidade ${ }^{55}$, bem como exprimem um entendimento suscetível a mudanças diacrônicas, na medida em que podem ser reforçadas ou alteradas ao longo do tempo, o que as diferentes versões da Classificação Internacional de Doenças e Problemas Relacionados à Saúde (CID) indicam.

Sobre a discutível distinção entre terapia e melhoramento e seu controverso papel na determinação da moralidade dos usos das biotécnicas, remeto-me às ponderações feitas por Kamm ${ }^{56}$, por Savulescu, Sandberg e Kahane ${ }^{57}$, bem como por Vilaça e Marques ${ }^{58}$, os quais destacam os problemas em torno de alguns conceitos que estão na base dessas distinções (doença e saúde, normal e anormal, tratamento e prevenção, curar e manipular, natural e artificial), tanto do ponto de vista teórico, quanto empírico e prático. Além de serem conceitos polissêmicos e móveis, portanto, relativamente imprecisos, há um forte desacordo em relação ao seu caráter/papel normativo, bem como severas objeções às suas implicações práticas. A título de exemplo, se as biotécnicas só fossem morais se usadas para curar uma doença, e não para ultrapassar uma normal geral ou promover o domínio sobre nossa natureza normal, vacinas (que não tratam doenças, mas melhoram/elevam a capacidade normal de imunidade) e contraceptivos (que envolvem formas de manipulação da biologia que dão às mulheres a possibilidade de dominar sua capacidade natural/normal de procriar, permitindo o planejamento da sua vida para atender aos seus desejos e propósitos) seriam biotécnicas imorais, entendimento irrazoável do ponto de vista secular.

\footnotetext{
${ }^{54}$ VILAÇA, M. M.; MARQUES, M. C. D. Tratar, sim; melhorar, não? Análise crítica da fronteira terapia/melhoramento. Revista Bioética (CFM), v. 23, n. 2, 2015, p. 267-276.

${ }_{55}$ ARAUJO, M. A ética do aprimoramento cognitivo: efeito Flynn e a falácia dos talentos naturais. Ethic@ (UFSC), v. 16, n. 1, 2017, p. 01-14.

${ }^{56}$ KAMM, F. What Is and Is Not Wrong with Enhancement? In: SAVULESCU, J.; BOSTROM, N. (Eds.). Human Enhancement. Oxford University Press, 2009, p. 91-130.

57 SAVULESCU; SANDBERG; KAHANE, op. cit., 2011.

${ }^{58}$ VILAÇA; MARQUES, op. cit., 2015.
} 
Como os argumentos de Sandel o retiram dos limites de uma ponderação razoável entre riscos e benefícios dos usos não terapêuticos das biotécnicas, mais do que uma ética do melhoramento, ele começa a delinear uma ética antimelhoramento.

$\mathrm{Na}$ análise crítica feita por Kamm ${ }^{59}$ acerca das alegações sandelianas, as objeções ao desejo de domínio e à insatisfação de viver com aquilo que nos é dado (given) pela natureza, por Deus ou pelo acaso são apontadas como os cernes da sua posição antimelhoramento. Com base nessas objeções fundamentais, Sandel, ainda segundo a filósofa, concentrar-se-ia na capacidade de nos melhorar e de melhorarmos os outros num ambiente competitivo, como veremos abaixo.

No capítulo 2, Sandel analisa o caso dos esportes. Ele começa o capítulo, intitulado de atletas biônicos, afirmando que

Um dos aspectos da nossa humanidade que pode estar ameaçado pelo melhoramento e pela engenharia genética é a nossa capacidade de agir livremente, por nós mesmos, graças a nossos esforços, e de nos considerarmos responsáveis (ou seja, dignos de orgulho ou censura) pelas coisas que fazemos e somos. Uma coisa é marcar setenta home runs [principal jogada do beisebol] como resultado de dedicação e treinamento e outra, menor, é conseguir o mesmo com a ajuda de esteroides ou de músculos geneticamente modificados. É claro que tudo é uma questão do grau de dedicação e de melhoramento envolvidos. Mas à medida que o grau do melhoramento aumentar, nossa admiração pelas conquistas diminuirá. Ou, melhor: nossa admiração pelas conquistas será transferida do jogador para seu farmacêutico. ${ }^{60}$

No texto, não fica claro que acepção do conceito de liberdade Sandel está adotando, nem a que tipo ${ }^{61}$ ele se refere, tampouco como e por que o melhoramento genético comprometeria a liberdade humana 'em geral'. Considerando que liberdade é um conceito complexo, polissêmico e multifacetado, isso é bastante problemático. Mas o mais fundamental é saber por que um atleta melhorado teria um déficit de liberdade. Ainda que isso pudesse ser verdade, caberia a Sandel o ônus de prová-lo argumentativamente, o que não faz. De todo modo, caso um biomelhoramento muscular, por exemplo, fosse capaz de solapar a liberdade humana como um todo, deveríamos assumir a posição antimelhoramento como inescapável. Contudo, se essa possibilidade for implausível, como penso que é, deveremos desconfiar do prognóstico anunciado, bem como das alegações que decorrem dele. Assim, como um mero prognóstico temerário, a ideia

${ }^{59}$ KAMM, op. cit., 2009.

${ }^{60}$ SANDEL, op. cit., 2013, p. 39.

${ }^{61}$ Pode-se falar em liberdade positiva, negativa, em liberdade em relação ao Estado e em relação aos outros indivíduos, em liberdade como ausência de obrigações e constrangimentos ou como poder de fazer o que se deseja, assim como em liberdade de locomoção, de expressão, de culto, consciência e crença, de expressão da atividade intelectual, artística, científica e de comunicação, etc. 
torna-se frágil, podendo representar não uma linha argumentativa consistente, mas um slogan de uma retórica antimelhoramento.

Outro ponto a ser destacado se refere ao que denominarei de opaca margem de melhoramento aceitável. Considerando que tudo é questão do grau de dedicação e de melhoramento envolvidos, não fica claro qual grau seria compatível com a justa admiração pelos feitos do atleta, com a manutenção da sua liberdade e responsabilidade pelo que ele é e faz. Se comparássemos os treinamentos envolvidos nos esportes de alta perfomance há menos de meio século com os que estão disponíveis atualmente, já teríamos que ter parado de assistir e torcer por quase qualquer atleta, uma vez que seus feitos poderiam, do ponto de vista de Sandel, ser mais corretamente atribuídos aos preparadores físicos, fisiologistas, nutricionistas, psicólogos, fabricantes de equipamentos e suplementos, etc. Embora o grau de melhoramento envolvido venha aumentando significativamente, não parece que nossa percepção sobre o mérito-responsabilidade dos atletas esteja se alterando proporcionalmente, o que pode indicar mais uma implausibilidade do prognóstico sandeliano.

Insistindo nesse ponto problemático, Sandel faz uma extrapolação indevida do exemplo. Agora, em vez do atleta melhorado, ele faz menção ao atleta biônico, que "[...] não seria responsável pelas suas 'realizações'; elas seriam de responsabilidade de seu inventor" ${ }^{62}$ Considerando que um atleta-humano-melhorado não pode ser comparado com um robô-atleta, penso que aquilo que valha para aquele, sem dúvida, não se aplica a este. Assim, a afirmação de que "de acordo com esse ponto de vista, ao erodir a função humana o melhoramento ameaça a humanidade", pois "sua expressão fundamental é um entendimento completamente mecanicista dos atos humanos, em desacordo com a liberdade humana e a responsabilidade moral" ${ }^{\prime 63}$, não parece dizer respeito ao biomelhoramento em si, mas à criação de um não humano, um autômato, um robô, que, certamente, não pode ser tido - pelo menos não até hoje - como livre e responsável, ao contrário do atleta-humanomelhorado, que pode. A forma como Sandel intitula um capítulo sobre os supostos problemas do melhoramento de atletas parece indicar uma má compreensão do que está precisamente, por assim dizer, em jogo (biônico e melhorado indicam configurações significativamente diferentes).

Embora reconheça que haja muito a dizer sobre o melhoramento do desempenho via engenharia genética, ele prossegue destoando do que tipicamente é alegado pelos críticos. Para Sandel, o principal problema do melhoramento e da engenharia genética não seria

[...] o fato de minarem a importância do esforço e diminuírem o papel do ser humano. O problema mais profundo é que elas representam uma espécie de superoperação, uma aspiração prometeica de remodelar a natureza, incluindo a natureza humana, para servir a nossos propósitos e satisfazer

${ }^{62}$ Ibid., p. 40.

${ }^{63}$ Ibid., p. 40. 
nossos desejos. O problema não é o desvio para o mecanismo, e sim o impulso à maestria, ao domínio. ${ }^{64}$

A questão central, para Sandel, não é salvaguardar o mérito legítimo por um esforço ou dedicação do atleta 'natural'. Conquanto esboce uma separação entre meios legítimos e ilegítimos (doping) de alcançar um bom resultado, uma boa performance, Sandel quer defender a noção de dádiva, que, no caso dos esportes, expressar-se-ia pelos dons ou talentos naturais. Segundo ele, "o crucial nos esportes não é a dedicação; é a excelência. E esta consiste, ao menos em parte, na exibição de talentos e dons naturais que não são mérito do atleta que os possui". ${ }^{65}$

Na perspectiva de Sandel, nas sociedades meritocráticas, há uma distorção do foco esportivo: "[...] aumentamos a relevância moral do esforço e da dedicação e depreciamos o talento natural"66, "queremos acreditar que o sucesso, nos esportes e na vida, é algo que conquistamos, e não algo que herdamos" ${ }^{67}$ Ele considera que o pecado do melhoramento não é fornecer formas de uma pessoa escapar do treino, mas sim que

[...] os atletas geneticamente modificados [...] corrompem a competição esportiva enquanto atividade humana que honra o cultivo e a exibição de talentos naturais. Desse ponto de vista, o melhoramento genético poderia ser encarado como a expressão máxima da ética da dedicação e do empenho, ou seja, como uma espécie de esforço high tech. Tanto a ética do empenho quanto os recursos biotecnológicos que agora estão a seu serviço vão contra as pretensões ao talento natural. ${ }^{68}$

Sandel admite que "o limite entre cultivar talentos naturais e corrompê-los com artifícios nem sempre é claro" de um esporte significa [...] fazer as regras de um modo que honrem as excelências cruciais para aquele esporte e recompensem as habilidades dos melhores jogadores". ${ }^{70}$ Sandel alega que

uma das bênçãos de nos ver como criaturas da natureza, de Deus ou do acaso é não sermos completamente responsáveis por aquilo que somos. Quanto mais nos tornamos mestres de nossas cargas genéticas, maior o fardo que carregaremos pelos talentos que temos e pelo nosso desempenho. ${ }^{71}$

Para ilustrar, Sandel dá um exemplo: “hoje, quando um jogador de basquete perde um rebote, o treinador pode culpá-lo por estar fora de posição. Amanhã o treinador poderá culpá-lo por ser baixo demais". ${ }^{22}$

\footnotetext{
${ }^{64}$ Ibid., p. 40.

${ }^{65} \mathrm{Ibid} .$, p. 41.

${ }^{66}$ Ibid., p. 42.

${ }^{67}$ Ibid., p. $41-42$.

${ }^{68}$ Ibid., p. 42.

${ }^{69}$ Ibid., p. 43.

${ }^{70}$ Ibid., p. 48.

${ }^{71}$ Ibid., p. 99.

${ }^{72}$ Ibid., p. 99.
} 
Algumas ponderações à alegação sandeliana e ao exemplo utilizado são pertinentes. Começando pelo exemplo, primeiramente, tal técnico deveria aprofundar seu conhecimento sobre os fatores que influenciam a estatura de um indivíduo. De acordo com as evidências científicas, sem excluir a importância dos fatores genéticos, cabe ressaltar que fatores ambientais, comportamentais e socioeconômicos influenciam significativamente a estatura de um indivíduo. ${ }^{73,74}$ Assim, a cobrança do técnico não estaria devidamente amparada no conhecimento científico.

Todavia, a questão mais fundamental é por que o indivíduo, e não seus pais ou os engenheiros genéticos, seria culpabilizado por ser 'baixo demais'? Se os fatores genéticos fossem completa e exclusivamente determinantes, e considerando que ele (atleta) não participou da escolha dos seus 'genes da baixeza', o técnico estaria equivocado novamente ao culpar o atleta. Restaria a ele culpar a natureza, o acaso ou Deus por não terem contemplado o atleta com a dádiva de uma 'boa' estatura; ou os pais, por não terem feito uma intervenção para 'corrigir' essa falta de dotação natural.

Tais equívocos revelam alguma ignorância acerca da biologia humana e de sua interface com o meio ambiente, o que não é infrequente no debate sobre biomelhoramento humano ${ }^{75}$, bem como uma má compreensão daquilo que confere ou não responsabilidade a alguém.

Gostaria, também, de destacar alguns controversos pontos de partida de Sandel: que o acaso ou Deus possam ser incluídos numa argumentação com pretensão moral universalista e secular; que a natureza, o acaso ou Deus poderiam ser intercambiáveis, não representando 'entidades' radicalmente distintas, que implicam visões de mundo não só distintas, mas, por vezes, antagônicas; que há algo como um talento natural dado pela natureza, pelo acaso ou por Deus a algumas pessoas e que, portanto, essas 'entidades' partilhariam a nossa responsabilidade pelo que somos ou fazemos; que o desempenho como resultado da dedicação e como expressão do talento são claramente discerníveis; que o talento é mais importante e honroso do que a dedicação; que não sermos responsáveis por tudo que somos e fazemos serve de base para criticar o melhoramento.

Sandel não desenvolve argumentos consistentes e, nalguns casos, sequer apresenta uma referência para sustentar o que alega. Algumas das suas alegações, inclusive, podem se transformar em petições de princípio, isto é, conclusões que são apresentadas como premissas. Desse modo, recorro

\footnotetext{
${ }^{73}$ BEUNEN, G. et al. Genetic Variance of Adolescent Growth in Nature. Annals of Human Biology, v. 27, issue 2, 2000, p. 173-186.

${ }^{74}$ PEDRAZA, D. F.; MENEZES, T. N. Fatores de risco do déficit de estatura em crianças pré-escolares: estudo caso-controle. Ciência E Saúde Coletiva (ABRASCO), v. 19, n. 05, 2014, p. 1495-1502.

${ }^{75}$ BUCHANAN, op. cit., 2011.
} 
a Buchanan ${ }^{76}$, para quem o apelo à gratidão, além de ser marcado pela imprecisão, não mostra como o truísmo de reconhecer que nem tudo é fruto do nosso esforço serviria como orientação prática para lidar com os desafios do melhoramento.

Em relação, mais precisamente, à alegação sandeliana de que devemos preservar certa sensibilidade de cunho marcadamente religioso, vendo "[...] nossos talentos como dons que recebemos e com os quais estamos em dívida em vez de como conquistas pelas quais somos responsáveis"77, e ao entendimento a ela articulado de que não devemos ser responsáveis por tudo o que somos, deixando humildemente a cargo do acaso, da natureza ou de Deus parte importante disso, pergunto: elas não dependeriam de certas crenças subjetivas que não podem ser exigidas de todos os agentes morais em sociedades pluralistas? Embora Sandel tente refutar a objeção de que sua defesa da noção de dádiva correlacionaria inescapavelmente seus argumentos a fundamentos religiosos - citando três filósofos (Locke, Kant e Habermas) de modo flagrantemente superficial e insuficiente - ele reconhece que "essa é uma questão profunda e difícil que não posso tentar resolver aqui". ${ }^{78}$ Nesse ponto, recorro a Araujo, para o qual "[...] a ideia de 'talentos' ou 'dons' ainda preserva resíduos da conotação religiosa e metafísica que essas palavras originalmente tinham". ${ }^{79}$

Outra objeção plausível diz respeito ao questionamento sandeliano sobre se deveríamos aspirar ao melhoramento humano. Na medida em que ele não oferece uma resposta amplamente plausível - que não abarque somente os que esposam determinadas concepções religiosas/metafísicas - sobre por que não deveríamos, seu questionamento assume um caráter quase frívolo, 'retórico', num sentido mais ordinário do termo.

Semelhantemente, ele não determina o porquê de não devermos buscar os nossos propósitos e satisfazer nossos desejos, exercendo domínio sobre a aquilo que chama de nossa natureza. Quanto a este último ponto, não seria justamente isso que fazemos por meio das terapias, buscando viabilizar o propósito de uma vida saudável, longa, com a menor quantidade de sofrimento possível, satisfazendo nosso desejo de felicidade e nosso propósito de florescer? Não parece haver dúvidas de que mudamos nossa natureza por meio de terapias, tampouco que, por meio dessas mudanças, expressamos nosso impulso a rejeitar coisas que nos foram dadas pela natureza, pelo acaso ou por Deus, mas que não considerados boas (doenças, deficiências, envelhecimento e afins), o que expressa nossa disposição de domínio sobre nossa natureza vulnerável.

\footnotetext{
${ }^{76}$ Ibid., 2011.

77 SANDEL, op. cit., 2013, p. 98.

${ }^{78}$ Ibid., p. 104.

${ }^{79}$ ARAUJO, op. cit., 2017, p. 5-6.
} 
Quanto à questão da liberdade humana, pode-se ponderar que, se uma das questões centrais for preservá-la, talvez uma argumentação plausível seria em favor da liberdade que pessoas teriam de não se melhorar, em razão de certas crenças subjetivas legítimas, sem que isso comprometa a liberdade que outras pessoas teriam de se melhorar. Uma proscrição absoluta do biomelhoramento, com base na pressuposição de uma entidade doadora e na imposição da sensibilidade humilde acerca da dádiva, pode representar uma forma arbitrária e ideológica de controle, algo prenhe de arrogância e, no limite, autoritário.

Ademais, tendo em vista a defesa de modalidades específicas de liberdade - como a de consciência e crença, que permite que pessoas pensem ou creiam que suas características naturais não são dádivas-dívidas a serem pagas com humildade e gratidão; bem como a morfológica, que garante a possibilidade de usar (ou não) técnicas de transformação corporal segundo a própria vontade, a fim de promover um plano de florescimento pessoal - parece-me que a proibição do biomelhoramento, ao contrário do que Sandel alega, comprometeria certas liberdades humanas, bem como obstaculizaria o florescimento de algumas pessoas.

Em suma, considerando os limites estabelecidos pela argumentação sandeliana, parece-me que a noção de dádiva, que pode servir para que algumas pessoas decidam não se melhorar, não serve para fundamentar uma posição contra o biomelhoramento em si. A meu juízo, seria falso ou falacioso presumir uma incompatibilidade radical entre a liberdade de não se melhorar e a liberdade de se melhorar. A falsa dicotomia, a falsa oposição, o falso dilema entre terapia ou melhoramento é um aspecto do debate que precisa ser reparado ou superado urgentemente.

Dito isso, a linha de raciocínio de Sandel - que pode ser razoavelmente endossada por alguns, por estar de acordo com suas doutrinas abrangentes sobre o bem viver - não atenderia aos requisitos de uma argumentação com pretensões morais pluralistas e universalistas, de modo que uma proscrição absoluta do biomelhoramento, por motivos morais seculares, não poderia ser sustentada com base nas alegações apresentadas por ele.

Passando para o caso abordado por Sandel no capítulo 3 (intitulado filhos projetados, pais projetistas), já no primeiro parágrafo do capítulo, o leitor é apresentado a uma hipótese aterrorizante: o melhoramento genético ameaça transformar os filhos em objetos, produtos e instrumentos dos seus pais. Sandel enceta sua abordagem com uma afirmação contundente e, a meu ver, panfletária:

valorizar os filhos como dádivas é aceitá-los como são, e não vê-los como objetos projetados por nós, ou produtos de nossa vontade, ou instrumentos de nossa ambição. $\mathrm{O}$ amor de um pai ou de uma mãe não depende dos talentos e atributos que o filho porventura tenha. ${ }^{80}$

${ }^{80}$ SANDEL, op. cit., 2013, p. 59. 
Tal afirmação serve de diapasão do tom adotado por ele no texto. Baseando-se, mais uma vez, em falsas oposições, falsas incompatibilidades, a saber, aceitar versus projetar, contemplar versus moldar, amar versus planejar, Sandel segue com sua retórica, no mínimo, frágil. A seguir, farei algumas ponderações sobre a procedência desse prognóstico moralmente catastrófico, analisando as alegações e seleções lexicais feitas por Sandel para defendê-lo.

Em primeiro lugar, chamo a atenção para um juízo de valor implícito no título do capítulo, isto é, que projetar é algo problemático ou negativo. Projetar ou planejar é uma atividade tipicamente humana, a qual expressa nossa capacidade de racionalizar o mundo. Esta se manifesta, por exemplo, nas capacidades de compreender relações de causa e efeito, de julgar e selecionar o que queremos para nós, de antecipar cenários futuros, de tomar decisões e se responsabilizar por elas, de buscar evitar danos, etc. Elas foram fundamentais no processo de modernização, secularização ou desencantamento do mundo, que nos libertou do domínio do destino fatalista de cunho religioso/ metafísico, da imprevisão e submissão absolutas. Dentre outras coisas, isso nos franqueou a possibilidade de autogoverno intramundano por meio da criação de domínios, incluindo o domínio médico-terapêutico, que deslocou certas características do incontrolável e imponderável campo da maldição/ punição divina para o campo da compreensão das anormalidades biológicas e intervenção sobre elas. Nesse sentido, utilizar a noção de dádiva contra o planejamento acarreta um retrocesso no modo como compreendemos o mundo, ensejando uma espécie de reencantamento dele.

Em segundo plano, ressalto que ele cria uma contraposição insidiosa, além de carente do mínimo de elementos de prova. Ao selecionar os termos objeto, produto e instrumento para se referir aquilo em que, na visão dele, os filhos seriam transformados, estabelecendo um contraponto com a seleção da palavra amor, ele introduz o que, considerando a diferenciação feita por Buchanan ${ }^{81}$ entre argumentação e retórica obscura, pode ser denominado de uma obscura retórica antimelhoramento. Contrapondo termos abjetos a um termo nobre, Sandel corre o risco de condenar o melhoramento açodada e sumariamente, injuriando-o, para usar o termo frequente na sua retórica antimelhoramento. Além disso, Sandel parece tomar a conclusão por premissa mais uma vez.

Citando o teólogo William F. May, Sandel quer defender que a relação entre pais e filhos é caracterizada fundamentalmente por uma abertura para o inesperado. Com base nisso, Sandel afirma que o problema do melhoramento "[...] reside na hybris dos pais projetistas, no seu impulso de controlar o mistério do nascimento".$^{82}$ A disposição de intervir e contro-

${ }^{81}$ BUCHANAN, op. cit., 2011.

${ }^{82}$ SANDEL, op. cit., 2013, p. 60. 
lar o mistério citado "[...] desfigura a relação entre ambos [pais e filhos] e priva os pais da humildade e do aumento da empatia humana que a abertura ao inesperado é capaz de promover". ${ }^{83}$ Para Sandel, "embora os tratamentos médicos intervenham na natureza, eles assim o fazem em nome da saúde e, portanto, não representam uma tentativa sem limites de maestria e dominação". ${ }^{44}$ Sandel segue, dizendo que "nem mesmo as mais extenuantes tentativas de tratar ou curar uma doença constituem um ataque prometeico àquilo que nos é dado". 85

Quanto a essas alegações, consideremos os exemplos do pré-natal e da terapia genética. Os exames que compõem o pré-natal são uma tentativa de acompanhar e, se necessário e possível, intervir sobre o desenvolvimento da descendência, com base no conhecimento que a ciência produziu, desvendando alguns mistérios da gestação, com vistas ao melhor nascimento. Como uma clara forma de exercer domínio sobre a natureza dos filhos, a fim de promover, do ponto de vista dos pais, o melhor nascimento e vida possíveis, o pré-natal é compreendido como um conjunto de cuidados que configura uma relação amorosa e empática entre os genitores e a descendência. Se, além dos exames tradicionais, incluirmos terapias genéticas - que, como vimos, Sandel considera desejáveis e moralmente admissíveis - não há dúvida de que os filhos podem ser mais propriamente algo parcialmente feito por nós (um projeto) do que algo completamente dado por alguma entidade metafísica (uma dádiva), o que não exclui, por completo, alguma imprevisibilidade. Aos pais, segue sendo imposta uma abertura amorosa e responsável acerca do inesperado, sem que isso lhes imponha uma aceitação dos filhos como uma postura irracional, indiferente e irresponsável de absoluta ausência de intervenção.

Embora siga reafirmando a diferença entre tratar e melhorar, Sandel dá vários indicativos textuais de que está ciente da sua imprecisão. Num ponto, ele diz que "como todas as distinções, o limite entre terapia e melhoramento se torna indistinto nos extremos. (Que dizer da ortodontia, por exemplo, ou da terapia com hormônio do crescimento no caso de crianças muito baixas?)". ${ }^{86}$ Noutro ponto, ele admite que "os defensores do melhoramento têm razão neste quesito: melhorar os filhos com o uso da engenharia genética é semelhante, em espírito, às práticas de puericultura pesadas e alta pressão que se tornaram tão comuns hoje" ${ }^{\prime \prime 7}$

Conquanto reconheça certa imprecisão do limite supracitado e que os problemas do modelo societário vigorante são expressos por práticas variadas, não se restringindo ao melhoramento, ele chama a atenção para

\footnotetext{
${ }^{83}$ Ibid., p. 60

${ }^{84}$ Ibid., p. 61.

${ }^{85}$ Ibid., p. 61.

${ }^{86}$ Ibid., p. 62.

${ }^{87}$ Ibid., p. 64.
} 
os dilemas éticos referentes aos 'aditivos' farmacológicos para incremento do desempenho, citando um exemplo de investimento no biomelhoramento cognitivo (metilfenidato). Para Sandel, assim como o uso de esteroides e outros estimulantes, ele é

[...] uma tentativa de adequação, uma forma de resposta à demanda competitiva da sociedade para melhorar o desempenho e aperfeiçoar nossa natureza. Essa demanda pelo desempenho e pela perfeição anima o impulso de injuriar o que nos é dado. É a fonte mais profunda do problema moral do melhoramento. ${ }^{88}$

Mas o próprio Sandel reconhece que há problemas na separação moral radical que alguns fazem quando comparam práticas ou meios sociais de adequação e práticas ou meios biotecnocientíficos que teriam a mesma finalidade:

Há quem veja uma linha distinta entre o melhoramento genético e as outras maneiras que as pessoas utilizam para melhorar a si mesmas e aos seus filhos. A manipulação genética parece de certa forma pior - mais invasiva, mais sinistra - do que outras maneiras de melhorar o desempenho e buscar o sucesso. Mas, do ponto de vista moral, a diferença é menos significativa do que parece. ${ }^{89}$

Assim, parece plausível inferir que, em conformidade com Sandel, há dúvidas sobre a procedência de uma das teses fundamentais do antimelhoramento, a saber, que biotécnicas de melhoramento trariam questões morais absolutamente novas e riscos proporcionalmente incomparáveis em relação a outros já existentes em outras práticas. Para Kamm ${ }^{90}$, por exemplo, até agora, não está claro por que o domínio terapêutico sobre a chamada natureza humana seria justificado, e o domínio melhorador não.

Pondo em destaque as incongruências presentes na retórica sandeliana, cito um trecho do epílogo do livro,

[...] existe uma diferença entre curar e melhorar. A medicina intervém na natureza, mas [...] não representa um ato de hybris desenfreada nem um apelo de dominação. A necessidade de curar vem do fato de que o mundo não é perfeito e completo, mas necessita constantemente da intervenção e reparação humanas. Nem tudo que nos é dado é bom". ${ }^{91}$

No trecho acima, ainda que inadvertidamente, Sandel parece ir de encontro com as teses centrais que defende ao longo do livro. Ao expressar uma não satisfação com a imperfeição e incompletude do mundo, afirmar que nem toda dádiva é boa e endossar a necessidade de intervenções e reparações

\footnotetext{
88 Ibid., p. 72.

${ }^{89}$ Ibid., p. 72-73.

${ }^{90}$ KAMM, op. cit., 2009.

91 SANDEL, op. cit., 2013, p. 111.
} 
constantes, Sandel admite que a natureza humana não é impermeável a modificações e a algum domínio, expondo sua controvertida retórica antimelhoramento a ainda mais fragilidades.

Reafirmar a diferença entre curar e melhorar não satisfaz as exigências argumentativas de fundamentação normativa da distinção entre terapia e melhoramento que justifique a proscrição moral deste. Por outro lado, no que diz respeito ao conjunto daquilo que nos teria sido dado pela natureza, pelo acaso ou por Deus, não parecem claras as razões normativas que fundamentam a separação entre o que devemos aceitar grata e humildemente e o que devemos rejeitar diligentemente. Se, conforme Sandel alega, o dado inato não deve ser dominado ou moldado, mas sim reverenciado e contemplado, exercer domínio sobre as doenças (destacadamente as congênitas ou inatas), moldando a natureza biológica para eliminá-las, não seria um ato de ingratidão e arrogância? Embora eu concorde com Sandel que nem tudo que nos é dado é bom e que, logo, podemos rejeitar coisas dadas que são tidas como más, o ponto é como preservar o valor argumentativo e normativo da dádiva contra o melhoramento.

À guisa de conclusão, cito um último trecho do livro de Sandel, no qual, a meu ver, está indicado que o problema da relação entre pais e filhos, na atualidade, não decorre propriamente do biomelhoramento:

A obrigação de moldar nossos filhos, de cultivá-los e melhorá-los complica o argumento contra o melhoramento. Admiramos os pais que buscam o melhor para seus filhos, que não poupam esforços para ajudá-los a conquistar a felicidade e o sucesso. Qual é, então, a diferença entre oferecer essa ajuda por meio da educação e da disciplina e fornecê-la por meio do melhoramento genético? Alguns pais conseguem vantagens para os filhos ao matriculá-los em escolas caras, contratar professores particulares, mandá-los a acampamentos de tênis, aulas de piano, de balé, de natação, de preparação para os exames de admissão à universidade e assim por diante. Se isso é admissível, e até mesmo admirável, então por que não é igualmente admirável que os pais se valham de quaisquer tecnologias genéticas à disposição (desde que sejam seguras) para melhorar a inteligência, a habilidade musical ou a competência esportiva dos seus filhos? ${ }^{92}$

Complementando os apontamentos críticos realizados acerca do conceito de dádiva e da sua pertinência para criticar o biomelhoramento, cito a crítica feita por Buchanan à retórica obscura mascarada como argumento, o que, reforço, caracteriza o debate:

[...] alguns escritores afirmam que a busca de melhoramento revela uma falta da virtude da "gratidão" pelo "dado", sem mesmo considerar que, falando propriamente, a gratidão é apropriada apenas em resposta a um benefício contido por um agente e, em particular, um benefício concedido

${ }^{92}$ Ibid., p. 63-64. 
intencionalmente. No entanto, esses escritores afirmam que o "argumento da gratidão" não se baseia na suposição de que "o dado" é um presente de Deus. Eles afirmam que as considerações de "gratidão" fornecem uma objeção poderosa ao melhoramento, ainda que o debate deva se restringir a um discurso público que seja acessível tanto aos não religiosos quanto aos religiosos. Alguém pode se sentir sortudo porque as contingências da evolução produziram um mundo no qual há tanta cor e beleza, mas seria estranho uma pessoa que fosse grata à evolução. ${ }^{93}$

Em suma, se o impulso ao domínio, a manipulação da natureza humana, a rejeição do que nos foi dado e a produção de adaptação não se restringem ao melhoramento, parece implausível recorrer a esses elementos para respaldar uma crítica específica aos usos não terapêuticos da engenharia genética.

Desse modo, em face da sua inconsistência argumentativa, a premissa da gratidão à dádiva-dívida teria que ser substituída por um parâmetro judicativo intramundano. Do ponto de vista da moralidade secular, a qual pode conviver com perspectivas religiosas de mundo tidas como razoáveis, algo ser considerado como uma dádiva pode ser relevante/determinante para alguns, mas nada relevante ou determinante para outros. O que importa é se compreendemos o dado como uma dádiva/benção a ser humildemente desfrutada; como uma maldição a ser aceita/expiada; como uma falta de sorte com a qual se pode apreender ou não a conviver; ou meramente como uma característica que podemos livremente querer e tentar modificar, para ajustá-la ao nosso projeto de florescimento.

Enfim, contra uma suposta concepção de perfeição inapropriadamente atribuída ao biomelhoramento, de pura adaptação ao imperfeito mundo meritocrático e performático, Sandel parece propor sua própria concepção de perfeição, da qual o melhoramento não faria parte. Destacando a legitimidade de uma perspectiva em favor da dádiva, cabe ressaltar, no entanto, que tal legitimidade depende, em parte, de não ser imposta arbitrariamente ao conjunto dos seres humanos de sociedades secularizadas e pluralistas. Dito de outro modo, a dádiva não pode ser usada para proscrever o biomelhoramento.

\section{Referências}

ARAUJO, M. A ética do aprimoramento cognitivo: efeito Flynn e a falácia dos talentos naturais. Ethic@ (UFSC), v. 16, n. 1, 2017, p. 01-14.

BAZZAN, M. R. A ideologização de 'Rousseau' no teatro da revolução francesa. Kriterion (UFMG), v. 61, n. 146, 2020, p. 481-500.

${ }^{93}$ BUCHANAN, op. cit., 2011, p. 3. 
BEUNEN, G. et al. Genetic Variance of Adolescent Growth in Nature. Annals of Human Biology, v. 27, issue 2, 2000, p. 173-186.

BOSTROM, N. A History of Transhumanist Thought. Journal of Evolution and Technology, v. 14, n. 1, 2005, p. 1-25.

BOSTROM, N. Transhumanist Values. Review of Contemporary, v. 4, issue 1-2, 2005, p. 87-101.

BOSTROM, N. et al. The Transhumanist FAQ. World Transhumanist Association, version 2.1. 2003, p. 4. Disponível em: https://www.nickbostrom.com/views/transhumanist.pdf. Acesso em: 16 nov. 2020.

BUCHANAN, A. Beyond Humanity? The Ethics of Biomedical Enhancement. Oxford: Oxford University Press, 2011.

DIAS, M. C.; VILAÇA, M. M. Metamorfoses do humano: notas sobre o debate ético em torno da biotecnologia para o aperfeiçoamento humano. Ethic@ (UFSC), v. 9, n. 1, 2010, p. 29-42.

DIAS, M. C.; VILAÇA, M. M. Natureza humana versus aperfeiçoamento? Uma crítica aos argumentos de Habermas contra a eugenia positiva. Princípios - Revista de Filosofia (UFRN), v. 20, n. 33, 2013, p. 227-263.

FUKUYAMA, F. Nosso futuro pós-humano: consequências da revolução biotecnológica. Rio de Janeiro: Rocco, 2003.

FUKUYAMA, F. Transhumanism - The World's Most Dangerous Idea. Revised Version, 2019. Disponível em: https://www.au.dk/fukuyama/boger/essay/. Acesso em: 17 nov. 2020.

GORDON, J-S.; BURCKHART, H.; SEGLER, P. Introduction. In: GORDON, J-S.; BURCKHART, H. (Eds.). Global Ethics and Moral Responsibility: Hans Jonas and His Critics. New York: Routledge, 2014, p. 1-8.

HABERMAS, J. O futuro da natureza humana: a caminho de uma eugenia liberal? São Paulo: Martins Fontes, 2004.

HARRIS, J. Enhancement Are a Moral Obligation. In: SAVULESCU, J.; BOSTROM, N. (Eds.). Human Enhancement. Oxford University Press, 2009, p. 131-154.

JONAS, H. O princípio responsabilidade: ensaio de uma ética para a civilização tecnológica. Rio de Janeiro: Contraponto; Ed. PUC-Rio, 2006.

JONAS, H. Técnica, medicina y ética: sobre la práctica del principio de responsabilidad. Barcelona: Paidós Ibérica Edicioones, 1997.

JUNGES, J. R. Falácia dilemática nas discussões da bioética. Revista Bioética, v. 27, n. 2, 2019, p. 196-203.

KAMM, F. What Is and Is Not Wrong with Enhancement? In: SAVULESCU, J.; BOSTROM, N. (Eds.). Human Enhancement. Oxford University Press, 2009, p. 91-130.

KASS, L. R. Life, liberty and the Defense of Dignity. San Francisco: Encounter Books, 2002.

KASS, L. R. et al. Beyond Therapy: Biotechnology and the Pursuit of Happiness. A Report by the President's Council on Bioethics. New York: Harper Collins, 2003. 
MORE, M. The Philosophy of Transhumanism. In: MORE, M.; VITA-MORE, N. (Eds.). The Transhumanist Reader. Chichester, UK: Wiley-Blackwell, 2013, p. 3-17.

PEDRAZA, D. F.; MENEZES, T. N. Fatores de risco do déficit de estatura em crianças pré-escolares: estudo caso-controle. Ciência \& Saúde Coletiva (ABRASCO), v. 19, n. 05,2014 , p. $1495-1502$.

SANDEL, M. Contra a perfeição: ética na era da engenharia genética. Rio de Janeiro: Civilização Brasileira, 2013.

SAVULESCU, J.; SANDBERG, A.; KAHANE, G. Well-Being and Enhancement. In: SAVULESCU, J.; MEULEN, R. t.; KAHANE, G. (Eds.). Enhancing Human Capacities. Oxford: Wiley-Blackwell, 2011, p. 3-18.

VILAÇA, M. M.; MARQUES, M. C. D. Tratar, sim; melhorar, não? Análise crítica da fronteira terapia/melhoramento. Revista Bioética (CFM), v. 23, n. 2, 2015, p. 267-276.

VILAÇA, M. M. Levando o transumanismo a sério - isso não é uma apologia! In: OLIVEIRA, J.; LOPES, W. E. S. (Orgs.). Transumanismo: o que é, quem vamos ser. Caxias do Sul: Educs, 2020, p. 135-160.

Endereço do Autor:

Escola Nacional de Saúde Pública (ENSP/DIHS)

Av. Brasil, 1480

Manguinhos

21041-210 Rio de Janeiro - RJ

contatoacademico@hotmail.com 